\title{
Process of registrations under food law: a comparative review of New South Wales and Sri Lankan contexts
}

\author{
Charith Amidha Hettiarachchi ${ }^{1 *}$, Sumal Nandasena ${ }^{2} \&$ Jon Wardle ${ }^{1}$ \\ ${ }^{1}$ Department of Public Health, Faculty of Health, University of Technology Sydney, NSW, Australia; ${ }^{2}$ Ministry of \\ Health, Sri Lanka
}

*Correspondence: dr.charith@gmail.com

https://orcid.org/0000-0002-7329-6581

DOI: https://doi.org/10.4038/jccpsl.v26i4.8370

Received on 8 June 2020

Accepted on 22 August 2020

\section{Introduction}

Registration is the initial step of food surveillance. Unlike registration as a departmental requirement (i.e. a regulatory instrument), legal registration is stronger as it is required by the law of the country (i.e. a legislative instrument). Legal registration is mandatory and failure to register becomes an offence.

The purpose of legal registration of a food business/premises is not only for surveillance, but it also serves as the backbone of food safety. Sri Lanka had introduced the registration process initially by the Food and Drug Act of 1949 (1), the predecessor of the current Food Act of 1980. The Sri Lankan Food Act of 1980 (2) re-introduced the process of registration; however the implementation process did not occur until gazetting of the Food (Registration of Premises) Regulations in 2019 (3). The enforcement date of said regulation is $1^{\text {st }}$ January of 2020 , meaning it took 20 years to implement the legal process of registration of food businesses premises in Sri Lanka.

Australia is a federal country constituted of six independent States and two Territories, each of which have their own Food Acts. However, all State and Territory Food Acts are directed and guided by the
Food Code passed by the central government of Australia and since extended to New Zealand, is a legal standard under "Food Standards Australia and New Zealand" (FSANZ) (4). Food Act 2003 (NSW) is the food law of the state of New South Wales (NSW) which follows the legal standards of FSANZ (5). The provisions for registration of food businesses are available in the Food Act 2003 (NSW).

This study aims to compare the process of food business premises registration in NSW and Sri Lanka. NSW was chosen as Australia's largest and oldest State jurisdiction and-due to FSANZ - its legislation is largely representative of Australian law. Since Sri Lanka is in the initial period of the registration process, this analysis helps to identify strengths and drawbacks in Sri Lankan system which in turn helps in future improvements.

\section{Methods}

The study is a comparative review of laws associated with registration of food businesses and premises in NSW (Australia's largest and oldest State) and Sri Lanka. A desk review was carried out using a check list, which was developed based on provisions within food legislations of NSW and of Sri Lanka. The check list was developed based on broad areas of 'definitions', 'registration process', 'conditions' 
'exemptions of registration', 'registration authorities', 'timeline of registration', 'duration of valid period' and 'fees'.

\section{Results and discussion}

The NSW law registers food businesses 'as an entity process', whereas Sri Lankan law registers premises 'as a location'. Therefore, the objective of registration is different in the two countries. The NSW model is similar to India which also registers food businesses rather than premises. The Consumer Protection Authority Act of 2003 of Sri Lanka stipulates to register businesses and similar provisions exist also in local government laws, but these tend to focus on consumer law or other provisions rather than on public health laws focused on food safety. The Sri Lankan approach on registering premises requires multiple registrations if the same business operates in multiple premises. However, in NSW, the licence is given only to permitted premises and food types, which are explicitly stated in the licence which restricts changes of the nature of food business, and thereby largely achieve the same outcome.

New South Wales and Sri Lankan definitions on 'food business/food premises' is given in Table 1. NSW has a single definition for 'food business' across legislation (5). Sri Lanka has two different - and sometimes inconsistent - definitions to 'food premises' in different legislation: one definition in the Sri Lankan Food Act of 1980 (2) and another in the Food (Registration of Premises) Regulations, 2019 (3). The definition given in the Food (Registration of Premises) Regulations, 2019 is more restricted as non-commercial food handling places are excluded. Additionally, the definition of premises under Food (Registration of Premises) Regulations, 2019 includes "surroundings under the control of the same management", which leads to potential confusion around boundaries. Legislators may also try to follow the definition of "Food Establishment" given in Food (Hygiene) Regulations, 2011 (6). By principle, there should be only one consistent definition, and the most valid definition is likely to be the definition given in the Food Act of 1980; the 'Mother Act' or 'Primary Act', which is held to have more authority over its regulations.
Businesses that need licensing and businesses that need notifying in NSW are shown in Table 2. In NSW, registration means either licensing or notifying, depending on the type of business. Certain businesses need to be licensed by the State Food Authority, whereas other businesses only need to be notified either at the State Food Authority or at the local council(5).

The NSW registration process is more practical than Sri Lankan registration process, as some businesses need a licence and others need only a notification. Small scale entrepreneurs need only notification of their business, which removes the relatively complex and expensive process of licensing for lower-risk businesses. Removal of such regulatory barriers may promote the economic growth of low- and middleclass people (business owners) as well as help improve the availability of foods in the markets. Sri Lanka does not have such differences and all premises are required to be registered (2) at the Food Authority.

In NSW, large-scale food businesses which can cause severe health outcomes are to be registered (licensing or notifying) with the Food Authority, which is the central body, whereas other lower risk concerns are notified to the Local Council. This is justifiable as Food Authority is the place which has more technical expertise and technical resources to oversee public health objectives. In comparison in Sri Lanka, all premises need to be registered with 'Food Authorities' which further differ from NSW in that they are localized bodies. For Municipal Council areas, the 'Food Authority' is the Municipal Council, whereas it is the medical officer of health in other areas, as Urban Council and 'Pradeshiya Saba' are not yet approved by the Health Minister as Food Authorities. Therefore, central control and oversight are lacking in Sri Lanka for all areas of food production except for bottle water manufacturers.

Exclusions for registration persist in both systems as shown in Table 3. The NSW explicitly excludes certain businesses from registration. Sri Lanka on the other hand has tried to exempt some premises by registration, but these exemptions cannot be precisely or explicitly identified due to ambiguity of the relevant provision in the Food (Registration of 
Premises) Regulations, 2019. These regulations offer two potential interpretations. The first interpretation is that the premises that need to be registered are the premises that handle food that provide goods to places set out in Schedule II of the regulations, rather than primarily the places set out in that schedule. The second interpretation is that the premises that need to be registered are explicitly the premises set out in Schedule II of the regulations. Fees for registration are stipulated in schedule $\mathrm{V}$ of the regulations. Since Schedule II and Schedule V of Food (Registration of Premises) Regulations, 2019 are different the most appropriate interpretation should be the first one. However, this first interpretation is also not fully precise, as inclusions such as 'bakery', 'ice cream, confectioneries, yoghurt, curd, dessert manufacturing cottage industry' and 'ice manufacturing premises' which are stipulated in Schedule II are manufacturing processed food in its own premises without buying from any other premises. On the other hand, Section 7 of the Food Act of 1980 stipulates to register (as amended in 1991) all premises irrespective of the type (2). Therefore, Section 2 of the Food (Registration of Premises) Regulations, 2019 conflicts with Section 7 of the Food Act of 1980. Legal principal is that any provision in a regulation which contravenes to the provision of the relevant 'Mother Act' or 'Primary Act', which is the Food Act of 1980 in this case, becomes null and void which ultimately leads to a final outcome of registering all premises. However, with the Food (Registration of Premises) Regulations, 2019 being enforced from January 2020 , it will be interesting to see how these conflicting interpretations are argued in magistrate courts, and possibly in higher courts during appeals.

Differences in various stages of the registration process between the two legal systems are outlined in Table 4. Being part of a developed country, NSW has widely adopted the latest technologies for registration such as online applications, online approvals and online payments, and therefore hardly any physical paperwork is required (although this option remains available). However, Sri Lanka even though it has the required technology as a country, the entire process remains manual and paper-based, potentially leading to reduced efficiency and accessibility.

A certificate is issued by both countries by the relevant Food Authority if registration is accepted after the inspection procedure. However, no certificate is issued for businesses which need only notification in NSW. Certificates are required to be displayed in the premises in both countries. Premises may include a vehicle according to the definition given by the Sri Lankan Food Act of 1980 though specific provisions are not made. In NSW, vehicles which handle food are issued a label or sticker in addition to the certificate. Therefore, the registration is more visible to consumers while Sri Lankan consumers do not have opportunities for such visibility. Display of a certificate in the vehicle is still possible, but a label or a sticker would be more consumer friendly. In NSW, there is a method of issuing a temporary licence, however no such provisions exist in Sri Lanka to handle cases of unexpected delays due to logistics, disaster and outbreak issues.

In NSW, licences are issued only after a food safety audit has been conducted by an auditing officer though, but this process is not required for notification (5). Sri Lanka also approves the registration only after an inspection by an Authorized Officer (3). The Registration process in NSW is more transparent and creates less opportunity for corruption compared to the Sri Lankan system, as separation of roles means that the inspection or auditory process for registration and prosecution are performed by separate parties. Specifically, trained auditors show higher efficiency as they are specially designated for that purpose. This spares the time of authorized officers too, allowing them to build greater capacity in their tasks. In Sri Lanka, the inspection procedure and prosecution are performed by the same authorized officer, which can lead to potential conflicts of interests and corruption. Sri Lanka does have third party options within the Ministry of Health as well as in other government organizations that could serve a similar role to that seen in NSW though they have not been involved in this capacity previously. Sri Lankan authorized officers are not specifically allocated for food hygiene, as they are also allocated for communicable 
and non-communicable diseases, school health and environmental health. Therefore, invariably the system runs towards inefficiency

Sri Lankan premises registration regulations have provided a long list of criteria to be inspected prior to registration. All types of premises share the same criteria. On the other hand, these criteria are named as 'specifications' contrary to the Food Act, 1980 which stipulate as conditions. Legal meaning of the 'condition' in commercial law is a term of an agreement which form the basis of the contract and determined by the intention of parties (7). Sales of Goods Ordinance of Sri Lanka (8) - as well as similar legislation in other common law countries like United Kingdom (9) - possesses a similar meaning. Violation of a condition leads to cancellation of the contract whereas other terms for which violations lead only to remedies are called warrants. Most of the specification stipulated in Food (Registration of Premises) Regulation, 2019 does not suit the definition of to be 'conditions' as per its legal meaning, which may result in further difficulties in enforcement.

The Food Act of 1980 of Sri Lanka - by its section 7 (3) - stipulates two types of conditions. The first type relates to the decision as to whether the premises should be registered or not. These conditions are required to be officially gazetted by the Health Minister as per Section 32 of the Food Act of 1980. The second type of condition is decided ad-hoc by the Food Authority at the time of issuing the certificate, and therefore the Food Authority can decide on conditions depending on the type of premises and circumstances at the time of issuing the certificate. These conditions cannot predetermine as they vary based on the type of premises and individual circumstances. However, food premises registration regulations in Sri Lanka have largely failed to identify - and apply - the differences of these two types of conditions.
NSW provides an estimate time from the day of inspection/audit. Therefore, unexpected delays are bearable. Sri Lankan regulations had tried to stipulate a maximum time limit from application to approval. However, this has not been successful as time limits are not stipulated for certain middle procedures such as subsequent inspections by authorized officers in case of deficiencies in the first inspection and for issuing certificates after the decision of regional director of health services (RDHS) in case of appeals.

Sri Lankan registration certificates need to be renewed every two years through a process that is similar to a new registration. This ensures the continuity of food safety and obligation of the owners to comply with food safety regulations. In NSW, there is no expiry of licences. However, unlike in NSW, the Sri Lankan Food Act of 1980 does not provide powers to Food Authorities to cancel the registration unless by a court order, and therefore automatic cancellations after two years is beneficial. However, due to lack of specifically allocated human resources, this might impact the continuity of the food business, and therefore more simplified processes may need to be introduced for renewal.

The fees structure in both countries is shown in Table 3. Notification is free in NSW though a fee is applied for licensing. The fee amount applied depends on the number of 'Full-Time Equivalent (FTE)' food handlers employed in the business. To calculate the FTE, the full-time working week is held to be 38 hours. To calculate the number of FTE food handlers employed by the business, all hours that food handlers are undertaking food handling activities in the business are added up and divided by 38 hours. In Sri Lanka, fees are not based on the number of food handlers or on hours work but rather on the type of food premises. 
Table 1: Definition of food business / premises

Australia (food business)

A business, enterprise or activity that involves: the handling of food intended for sale, or the sale of food: regardless of whether the business, enterprise or activity concerned is of a commercial, charitable or community nature or whether it involves the handling or sale of food on one occasion only
Sri Lanka (food premises)

Definition in the Food Act

Any shop, stall, or place where any food is sold or manufactured or stored for sale

\section{Definition in the regulation}

any building or are in which food is handled for commercial purposes and its surroundings under the control of the same management

Table 2: Food business need licensing / notifying in Australia

\begin{tabular}{ll}
\hline \multicolumn{1}{c}{ Licensing } & \multicolumn{1}{c}{ Notifying } \\
\hline $\begin{array}{l}\text { - Business related to egg, dairy meet, sea food and } \\
\text { plant products, }\end{array}$ & $\begin{array}{l}\text { To Food } \text { Authority } \\
\text { Home-based food businesses that do not retail their } \\
\text { product from the home premises, Importers that do } \\
\text { persons such as to hospitals patients and aged care } \\
\text { facilities }\end{array}$ \\
$\begin{array}{l}\text { not retail their product from their business premises, } \\
\text { small egg farms (fewer than 20 dozen eggs/week), } \\
\text { small poultry meat farms } \\
\text { (growing fewer than } 10 \text { birds) and businesses that } \\
\text { transport live poultry }\end{array}$ \\
$\begin{array}{l}\text { To local council } \\
\text { Restaurants; cafe's and takeaways, mobile food } \\
\text { outlets, food stall holders at regular, temporary } \\
\text { or one-off events, grocery stores and supermarkets, } \\
\text { businesses which sell food as a smaller part of their } \\
\text { business such as chemists, cinemas, corner stores, } \\
\text { petrol stations and sporting facilities, childcare } \\
\text { providers that provide food, school canteens, } \\
\text { importers of food or ingredients that retail the } \\
\text { product from their business premises and seafood r } \\
\text { etailers (unless they hold a Food Authority licence) }\end{array}$ \\
\end{tabular}

Table 3: Exclusions for registration

\begin{tabular}{ll}
\hline \multicolumn{1}{c}{ New South Wales } & \multicolumn{1}{c}{ Sri Lanka } \\
\hline $\begin{array}{l}\text { Events, charities and non-profits } \\
\text { Primary production food businesses } \\
\text { (such as farmers - other than dairy, egg or poultry }\end{array}$ & According to the Act \\
meat farms) & Does not excludes any premises \\
Fishing & $\begin{array}{l}\text { According to the regulation } \\
\text { It is not clear whether it excludes premises in } \\
\text { schedule 1 or premises which provide food to } \\
\text { premises in schedule } 1 .\end{array}$ \\
\hline
\end{tabular}


Table 4: Process of registration

\begin{tabular}{ll}
\hline \multicolumn{1}{c}{ New South Wales } & \multicolumn{1}{c}{ Sri Lanka } \\
$\begin{array}{l}\text { Registration/notification can be done by hand, by post } \\
\text { or by online }\end{array}$ & $\begin{array}{l}\text { Registration/notification can be done by hand or } \\
\text { by post only }\end{array}$ \\
$\begin{array}{l}\text { A licence is issued } \\
\text { A temporary license can be issued License is issued }\end{array}$ & $\begin{array}{l}\text { A temporary certificate cannot be issued } \\
\text { Certificate is issued after an inspection }\end{array}$ \\
$\begin{array}{l}\text { after a food safety audit } \\
\text { nuditing Officer is a third party (Auditory Officer) who }\end{array}$ & $\begin{array}{l}\text { Inspecting officer is the same party (Authorized } \\
\text { Officer) who involve in prosecutions }\end{array}$ \\
$\begin{array}{l}\text { Audit guidelines vary depending on the type of food } \\
\text { business }\end{array}$ & $\begin{array}{l}\text { Same inspection available for all types of } \\
\text { premises }\end{array}$ \\
Has specified the time limits & $\begin{array}{l}\text { Has specified the time limits } \\
\text { License does not expire unless cancelled }\end{array}$
\end{tabular}

Table 5: Fees of registration

\begin{tabular}{|c|c|}
\hline Australia & Sri Lanka \\
\hline$<5 F T E$ & Hotel or large resort (4 star or above) \\
\hline$\$ 390$ (Rs. 48,250) & Rs.50, $000(\$ 405)$ \\
\hline 5-50 FTE & Hotel or medium resort (3 star) \\
\hline$\$ 800$ (Rs. 98,900) & Rs.30, $000(\$ 245)$ \\
\hline$>50 \mathrm{FTE}$ & Hotel or large resort (all other) \\
\hline \multirow[t]{14}{*}{$\$ 3500$ (Rs. 432,700) } & Rs.20, $000(\$ 165)$ \\
\hline & Catering establishment \\
\hline & Rs.10, $000(\$ 80)$ \\
\hline & Supermarkets \\
\hline & Rs.10, $000(\$ 80)$ \\
\hline & Restaurant or eating house \\
\hline & Rs.5000 (\$40) \\
\hline & Ice cream, confectioneries, yoghurt, curd, dessert \\
\hline & manufacturing cottage industry \\
\hline & Rs.5000 (\$40) \\
\hline & Food manufacturing or processing facility \\
\hline & Rs.5000 (\$40) \\
\hline & All other \\
\hline & Rs.3000 (\$25) \\
\hline
\end{tabular}




\section{Conclusions and Recommendations}

Registration of premises instead of businesses is reasonable in the Sri Lankan context. However, the disparities in interpretation of the term 'premises' need to be cleared. This can be resolved by adopting the same definition stipulated in Food Act of 1980 by the Food (Registration of Premises) Regulations, 2019 or by explicitly referring to the definition in the Food Act of 1980 itself. The type of premises needing registration is misleading in the Sri Lankan Food (Registration of Premises) Regulations, 2019 and appears to contravene the Food Act of 1980 of Sri Lanka. Therefore, all premises should be registered, as stipulated in the Food Act of 1980 until the Food Act of 1980 is revised to adopt a simplified method, such as that observed in NSW, Australia.

If the inspection of premises for registration is done by a third party - as it is in NSW - other than authorized officers, it would improve the transparency as well as efficiency of the processes in Sri Lanka. As inspection procedures are not stipulated by the Food Act of 1980, there is no legal barrier to adopt such procedures. The specification stipulated by the Food (Registration of Premises) Regulations, 2019 does need to be revised and should be aligned with the directives given by the Food Act of 1980. Similarly, current single inspection format is not appropriate to all food premises and different inspection formats need to be developed similar to NSW.

\section{Public Health Implications}

Sri Lanka started registration of food premises in 2020 after a long wait since the enactment of Food Act of 1980. Therefore, registration is a process that is still novel in the Sri Lankan context. Analysing the Sri Lankan law with regards to registration of food premises is important to understand the possible practical implications of the law. Additionally, as this registration is mostly performed by an $\mathrm{MOH}$ as the Food Authority in Urban Council and Pradeshiya Saba areas, an in-depth analysis of the process that offers practical insights is of public health importance.
Australia as a developed country had started this process long time ago with modern technology, and its processes and infrastructure are well-developed and welltested in practice and in law. By comparing with Australia's largest jurisdiction NSW, drawbacks and strengths of the existing Sri Lanka registration process can be identified, and such insights may serve as guidance to Sri Lanka to highlight the amendments in the law in future.

\section{Author declaration}

Competing interests: No competing interests. None of the authors have competing interests.

Ethics approval and consent: Since this is a desk review of open access of public documents, consent and ethical approval are not relevant.

Funding: No funding was necessary for the desk review.

Acknowledgements: We sincerely appreciate the academic and non-academic staff of Department of Public Health, Faculty of Health, University of Technology Sydney and the Post Graduate Institute of Medicine, University of Colombo and Ministry of Health Sri Lanka for their valuable assistance.

Author contributions: CAH reviewed the literature, compared Sri Lankan Regulations with Codex Standards and wrote the manuscript. JW and SN were reviewed scientific process and writing of the study.

\section{References}

1. Department of Government Information. Food and Drug Act of 1949, Sri Lanka. Colombo: Government Publication Bureau.

2. Department of Government Information. Food Act of 1980, Sri Lanka. Colombo: Government Publication Bureau.

3. Department of Government Information. Food (Registration of Premises) Regulations 2019, Sri Lanka. Colombo: Government Publication Bureau. 
4. Federal Register of Legislation 2020. Australia New Zealand Food Standard Code, Australian Government. Available from: https://www. legislation.gov.au/Series/F2015L00386.

5. NSW Legislation. Food Act 2003 No 43, NSW Government. Available from: https://www. legislation.nsw.gov.au./

6. Department of Government Information. Food (Hygiene) Regulations 2011, Sri Lanka. Colombo: Government Publication Bureau.
7. Casemine. Maredelanto Compania Naviera SA v Bergbau-Handel GmbH. (The Mihalis Angelos). Available from: https://www. casemine.com/ judgement/uk.

8. Department of Government Information. Sale of Goods Ordinance No 11 of 1896, Sri Lanka. Colombo: Government Publication Bureau.

9. UK Public General Acts. Sales of Good Act 1979, United Kingdom. Available from: http://www. legislation.gov.uk./ 